\title{
Penilaian kualitas visual dan aspek sapta pesona pada lanskap Bali Zoo di Desa Pakraman Singapadu, Gianyar
}

\author{
I Kadek Ari Kurniawan ${ }^{1}$, Anak Agung Gede Sugianthara ${ }^{1 \star}$, Anak Agung Made Astiningsih²
}

1. Prodi Arsitektur Pertamanan, Fakultas Pertanian, Universitas Udayana, Indonesia 80232

2. Prodi Agroekoteknologi, Fakultas Pertanian, Universitas Udayana, Indonesia, 80232

*E-mail: sugianthara@unud.ac.id

\begin{abstract}
Assessment of the Visual Quality and Sapta Pesona Aspect on Bali Zoo Landscape in Singapadu Traditional Village, Gianyar. Bali Zoo is one of the artificial landscapes in the form of a zoo with educational, conservation, and tourism functions. This zoo has a vision to make Bali Zoo as an international zoo standards. Some efforts that can be done to realize the vision is by improving the aesthetic quality and aspects of sapta pesona. The assessment of visuals quality and aspects of sapta pesona in Bali Zoo aims to evaluate both visuals quality and sapta pesona aspect in the Bali Zoo landscape. Methods used in this research was field survey with observation, questionnaire, interview, and literature review techniques. The result was a description of the assessment of visuals quality and aspects of sapta pesona on Bali Zoo landscape, therewith recommendation that can be given in the form of recommendation might improve the visuals quality and aspects of sapta pesona on Bali Zoo landscape. It is concluded that the visuals quality and aspects of sapta pesona on Bali Zoo landscape were quite good and it can improve the aesthetic visuals quality of Bali Zoo landscape by improving the quality of landscape elements, whereas improving the aspects of sapta pesona from the elements of security, discipline, hygiene, beauty, coolness, friendliness, memory. These recommendation was suitable to apply by the manager, visitors and students.
\end{abstract}

Keywords: Bali zoo, sapta pesona, Singapadu, visual quality assessment

\section{Pendahuluan}

Kebun binatang merupakan wadah memelihara satwa yang dipertunjukkan kepada publik dengan habitat buatan. Kebun binatang memiliki fungsi yakni edukasi, konservasi dan juga wisata (Putri, 2014). Wisata alternatif di Kabupaten Gianyar yang sering dikunjungi sebagai tempat mengenalkan aneka satwa dan tumbuhan kepada masyarakat adalah objek wisata Bali Zoo. Berdasarkan situs resmi Bali Zoo (2017), Bali Zoo adalah kebun binatang yang dihuni oleh 450 ekor satwa yang berada pada masing-masing kandang yang telah direkayasa sedemikian rupa. Bali Zoo mempunyai visi menjadikan Bali Zoo sebagai kebun binatang bertaraf internasional. Sehingga, untuk mewujudkan visi tersebut Bali Zoo harus mengupayakan kegiatan berupa, peningkatkan kualitas dan kuantitas satwa, peningkatan kualitas lingkungan serta mewujudkan kondisi sapta pesona guna menciptakan suasana menarik dan nyaman bagi satwa maupun pengguna Bali Zoo. Adapun sapta pesona terdiri dari unsur keamanan, ketertiban, kebersihan, kesejukan, keindahan, keramahan dan kenangan. Menurut Sinaga (2010), citra dan mutu pariwisata suatu daerah atau objek wisata pada dasarnya ditentukan oleh keberhasilan dalam mewujudkan aspek sapta pesona pada daerah atau objek wisata.

Berdasarkan wawancara dengan pengelola satwa Bali Zoo, dijelaskan bahwa kejadian satwa yang keluar dari kandang masih sering terjadi, sehingga hal ini dapat menimbulkan bahaya bagi pengguna kebun binatang maupun bagi masyarakat sekitar. Kejadian tersebut terjadi dikarenakan kurangnya rasa nyaman bagi satwa dan sistem pengamanan kandang satwa yang kurang baik. Selain itu, terdapat pula permasalahan seperti aroma yang tidak sedap yang juga tercium dari kandang tertentu seperti kandang rusa dan kandang burung.

Oleh karena itu, penelitian ini perlu dilakukan dengan tujuan untuk dapat mempertahankan bahkan meningkatkan kualitas lingkungan, keindahan lansekap serta menambah kenyamanan lansekap Bali Zoo, sehingga dapat dinikmati dengan baik oleh pengguna. Upaya yang dilakukan untuk memenuhi aspek tersebut adalah dengan menilai keindahan lansekap dan aspek sapta pesona Bali Zoo sehingga lansekap pada Bali zoo yang aman, nyaman dan indah secara visual dapat tercapai. 


\section{Metode Penelitian}

Penelitian dilaksanakan di Bali Zoo, berlokasi di Desa Pakraman Singapadu, Kecamatan Sukawati, Gianyar. Luas Bali Zoo mencapai sembilan hektar, berada di ketinggian 100 mdpl. Penelitian berlangsung dari bulan Februari hingga Desember 2017.

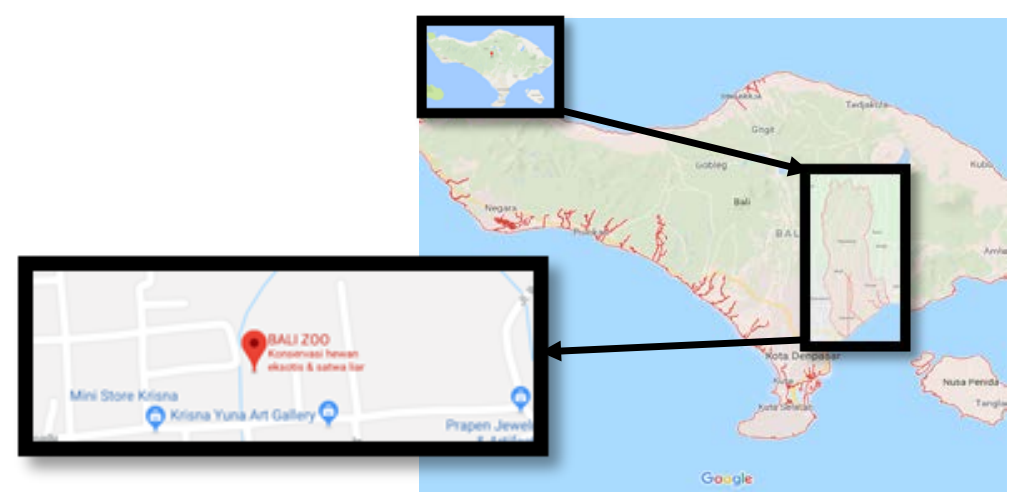

Gambar 1. Lokasi penelitian

Alat dan bahan yang digunakan dalam proses penelitian berupa alat tulis, lembaran kuisioner dan wawancara, kamera digital, dan perangkat komputer dengan piranti lunak Autocad 2010 dan Adobe Photoshop CS 3. Metode yang digunakan dalam penelitian adalah metode survei, dengan teknik pengumpulan data observasi, penyebaran kuisioner, wawancara, dan studi pustaka.Penelitian dilakukan di Bali Zoo, dengan ruang lingkup penelitian yaitu penilaian kualitas visual lansekap, penilaian aspek sapta pesona, dan usaha-usaha yang harus dilakukan untuk meningkatkan kualitas visual lansekap dan aspek sapta pesona Bali Zoo. Tahap studi dilakukan dengan pengumpulan data, analisis, dan sintesis.

\section{Hasil dan Pembahasan}

\subsection{Gambaran Umum}

Bali Zoo resmi menjadi Lembaga Konservasi Ex-situ melalui SK Menteri Kehutanan RI No. 68/KptsII/2001 tertanggal 15 Maret 2001 (Bali Zoo, 2017). Bali Zoo berlokasi di Desa Pakraman Singapadu, Kecamatan Sukawati, Kabupaten Gianyar, Provinsi Bali. Koleksi fauna Bali Zoo yang dapat dinikmati oleh pengunjung pada saat ini berjumlah 450 ekor satwa. Bali Zoo menyuguhkan aktivitas wisata berbeda, penuh dengan unsur pendidikan dan memanjakan mereka yang memiliki ketertarikan terhadap satwa.

\subsection{Penilaian Kualitas Visual Lansekap}

Berdasarkan penilaian responden (30 responden arsitek lansekap), kualitas visual lansekap Bali Zoo, terdiri dari kategori kurang baik; kategori cukup baik; kategori baik; dan kategori sangat baik. Kualitas visual lansekap merupakan suatu pengertian yang tidak nyata seperti kualitas tinggi, rendah, atau suatu kualitas yang mempunyai pengertian dari suatu visual lansekap. Titik lansekap Bali Zoo yang telah dinilai berjumlah 60 titik lansekap.

\subsubsection{Penilaian Kualitas Visual Lansekap Kategori Kurang Baik}

Responden menyatakan empat titik lansekap Bali Zoo dengan kualitas visual lansekap kategori kurang baik, yaitu titik lansekap 22, 37, 38 dan 43 (Gambar 4).

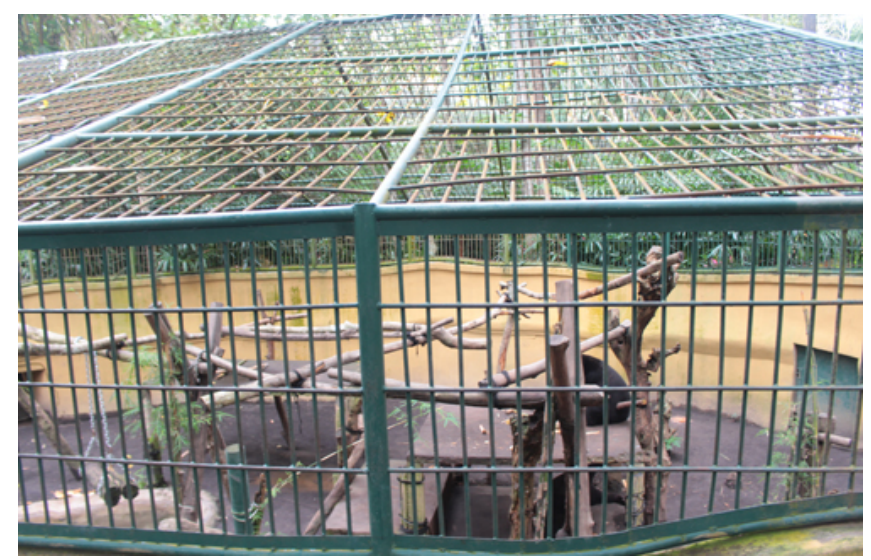

Gambar 2. Titik Lansekap dengan Kualitas Visual Kurang Baik 
Lansekap dengan kualitas visual kurang baik didominasi oleh elemen bangunan dengan kualitas bangunan kurang baik dan kurang menarik serta elemen vegetasi yang minim, tidak tertata. Berdasarkan pengamatan, lansekap Bali Zoo yang memperoleh penilaian kualitas visual kurang baik didominasi oleh vegetasi berwarna hijau, sehingga menimbulkan kesan monoton dan tidak menarik secara visual. Terlihat cat kandang satwa yang mulai nampak kurang baik serta pembatas besi yang mulai mengkarat. Elemen air, berupa kolam dan parit pembatas kandang satwa kotor akibat banyak sampah.

Usaha peningkatan kualitas visual lansekap Bali Zoo yang memperoleh penilaian kurang baik sangat perlu dilakukan. Usaha yang dapat dilakukan yaitu penambahan elemen vegetasi yang memiliki kelebihan pada warna, warna daun maupun warna dari bunga seperti, tanaman andong (Cordyline fruticosa), puring (Codiaeum variegatum), palem merah (Cyrtostachys renda), paku tanduk rusa (Polypodiaceae bifucatum), kaladi red star (Caladium bicolor) dan tanaman anggrek. Tanaman hias yang mempunyai bentuk, ukuran dan tekstur yang unik juga dapat difungsikan sebagai focal point untuk memusatkan perhatian. Tanaman tersebut seperti tanaman bunga kupu-kupu (Bauhinia blakeane), bunga lampion (Brownea grandiceps), sawo kecik (Manilkara kauki Dup.), cemara norflok (Araucaria heterophylla), pisang kipas (Ravenala madagascariensis). Penataan elemen vegetasi yang baik akan meningkatkan kualitas visual suatu lansekap. Meliawati (2003) menyatakan bahwa penggunaan elemen lansekap harus disertai dengan penataan dan pemeliharaan yang baik agar lansekap tampak indah dan lestari. Usaha peningkatan kualitas fisik bangunan dapat dilakukan dengan pengecatan kembali kandang satwa yang mulai menampakan warna kurang baik. Elemen air berupa kolam buatan dapat ditambah tanaman air berbunga agar terlihat lebih menarik, seperti tanaman teratai (Nymphaea), lotus (Nelumbo nucifera), dan melati air (Echinodorus palifolius).

3.2.2. Penilaian Kualitas Visual Lansekap Kategori Cukup Baik

Berdasarkan penilaian responden, dinyatakan 24 titik lansekap Bali Zoo dengan kualitas visual lansekap cukup baik, yaitu titik lansekap 01, 06, 07, 08, 09, 10, 12, 13, 14, 16, 17, 18, 19, 20, 21, 26, 27, 28, 29, 35, 36, 40, 44, dan 52 (Gambar 4). Karakter menonjol dari lansekap dengan kualitas visual kategori cukup baik adalah elemen vegetasi masih cukup dominan, namun penataannya masih kurang rapi. Berdasarkan survei, vegetasi yang dominan warna hijau masih mendominasi lansekap Bali Zoo yang memperoleh penilaian kualitas visual cukup baik, sehingga kurang menarik perhatian dan cendrung menurunkan kualitas lansekap. Keberadaan elemen bangunan dan perkerasan cukup seimbang. Hasil penelitian ini didukung oleh penelitian Meliawati (2003) yang menyatakan, bahwa lansekap dengan kualitas estetika sedang memiliki proporsi elemen vegetasi yang cukup seimbang dengan elemen bangunan dan perkerasan, dan secara umum terlihat cukup baik. Penggunaan perkerasan jalur pengunjung kurang menarik yang didominasi oleh bahan beton. Elemen air berupa kolam buatan diciptakan untuk menambah kesan alami, namun kolam yang tersedia terlihat kotor dengan air tidak jernih.

Peningkatan kualitas visual lansekap Bali Zoo yang memperoleh penilaian cukup baik perlu dilakukan. Penambahan elemen vegetasi dengan bentuk unik dan memiliki kelebihan unsur warna akan dapat meningkatkan kualitas lansekap secara visual. Transisi elemen vegetasi dengan variasi tekstur, warna, bentuk ukuran dalam urutan yang logis akan mampu menciptakan kesan alami. Usaha penyulaman dapat dilakukan terhadap tanaman yang rusak maupun mati. Jalan setapak dengan perkerasan berupa paving dengan motif tertentu akan terlihat lebih menarik dibandingkan dengan jalan setapak plesteran beton. Lansekap dengan kualitas estetika tinggi, memiliki kualitas material perkerasan yang cukup baik (Ruswan, 2006). Elemen air berupa kolam buatan juga dapat ditambah dengan tanaman air berbunga, guna meningkatkan nilai estetika.

\subsubsection{Penilaian Kualitas Visual Lansekap Kategori Baik}

Berdasarkan penilaian responden, diperoleh 25 titik lansekap Bali Zoo dengan kualitas visual lansekap baik, yaitu titik lansekap 04, 05, 11, 15, 23, 25, 31, 32, 33, 34, 39, 41, 42, 45, 46, 47, 48, 49, 51, 53, $55,56,57,58$, dan 59 (Gambar 4). Lansekap dengan kualitas visual baik, didominasi oleh elemen vegetasi dan air. Bali Zoo dengan kualitas visual baik terlihat dari elemen vegetasi yang tertata dengan baik dan rapi, baik dari segi penanaman maupun proporsinya. Pernyataan tersebut ditunjang oleh pernyataan Meliawati (2003) yang menyatakan, bahwa karakter yang menonjol dari lansekap dengan kualitas estetika baik adalah proporsi vegetasi yang cukup dominan, sehingga terkesan teduh dan nyaman. Elemen air pada lansekap Bali Zoo berupa kolam dan parit pembatas kandang satwa. Meliawati (2003) menambahkan, bahwa semakin besar proporsi elemen air dalam suatu lansekap akan meningkatkan kualitas estetika lansekap tersebut.

Berdasarkan observasi, lansekap Bali Zoo yang tergolong dalam kualitas visual lansekap baik masih perlu ditingkatkan dari segi elemen vegetasi. Penambahan elemen vegetasi yang memiliki kelebihan pada warna, baik warna pada daun maupun bunga akan dapat meningkatkan nilai estetika, sehingga semakin indah untuk di pandang. Memainkan transisi tanaman dengan variasi tekstur, bentuk, tinggi, ukuran dalam urutan yang harmonis akan menimbulkan kesan alami. Penambahan elemen lansekap sebagai focal point juga dapat difungsikan untuk memusatkan perhatian. Kolam yang tersedia pada tapak sebaiknya 
ditambahkan dengan tanaman air berbunga agar terlihat lebih menarik. Kebersihan elemen air juga perlu ditingkatkan, terlihat kolam buatan dan parit pembatas kandang satwa yang kurang bersih. Kebersihan merupakan salah satu unsur untuk menunjang peningkatan kualitas estetika secara visual.

3.2.4 Penilaian Kualitas Visual Lansekap Kategori Sangat Baik

Berdasarkan penilaian responden, diperoleh tujuh titik lansekap Bali Zoo dengan kualitas visual lansekap kategori sangat baik, yaitu titik lansekap dua, tiga, 24, 30, 50, 54, dan 60 (Gambar 4). Titik lansekap yang memperoleh penilaian sangat baik sebagian besar merupakan titik-titik lansekap area Kampung Sumatera Bali Zoo. Berikut merupakan salah satu titik lansekap yang memperoleh penilaian kualitas visual sangat baik.

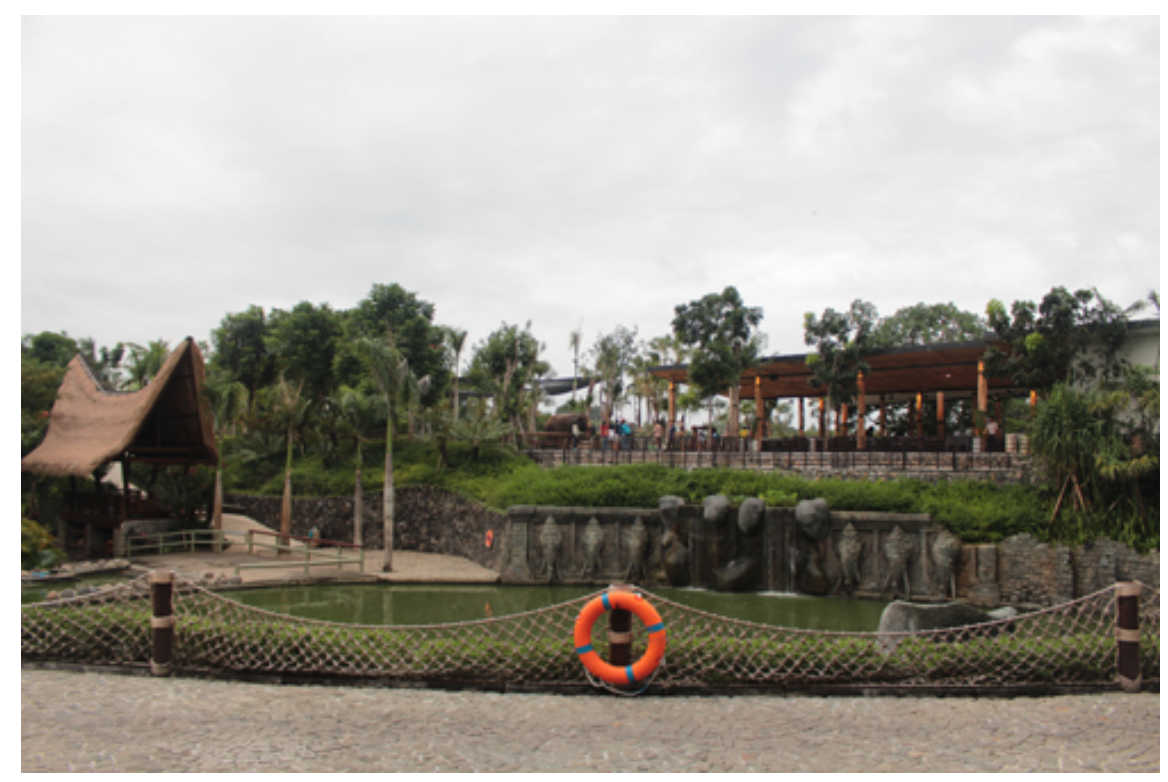

Gambar 3. Titik Lansekap dengan Kualitas Visual Sangat Baik

Karakter yang menonjol dari titik lansekap dengan kualitas visual kategori sangat baik adalah komposisi antara elemen lansekap harmonis. Berdasarkan wawancara dengan arsitek Bali Zoo (Gede, 2017) menyatakan, bahwa tapak Kampung Sumatera didesain lebih modern dibandingkan area Zoo, elemen lansekap yang digunakan juga lebih baik. Tapak ini didominasi oleh vegetasi dengan penataan, bentuk, ukuran yang baik. Berdasarkan penelitian Laila (2002), lansekap dengan kualitas estetika tinggi dicirikan oleh terdapatnya vegetasi pohon dan semak yang tertata dengan baik. Vegetasi semak berbunga yang tersedia akan meningkatkan kualitas estetika pada saat musim tertentu. Elemen bangunan yang tersedia berupa restoran dan bangunan plaza mengadopsi atap bangunan khas Sumatera. Umumnya lansekap yang termasuk ke dalam kualitas estetika tinggi, elemen bangunannya memiliki arsitektur yang baik, sehingga dapat memperkuat karakter lansekap tersebut dan dapat meningkatkan kualitas estetikanya (Ruswan, 2006). Elemen perkerasan sangat baik, jalan setapak berupa paving blok dan jalan setapak dengan berbagai motif bunga maupun dedaunan. Elemen air yang tersedia berupa kolam gajah yang dipadukan dengan perkerasan berupa karya seni berbentuk kepala gajah sebagai media air mancur sehingga menambah kesan alami. Lansekap dengan penilaian kualitas visual sangat baik harus dijaga, dipertahankan bila perlu ditingkatkan agar lansekap tampak indah dan lestari secara berkelanjutan. 

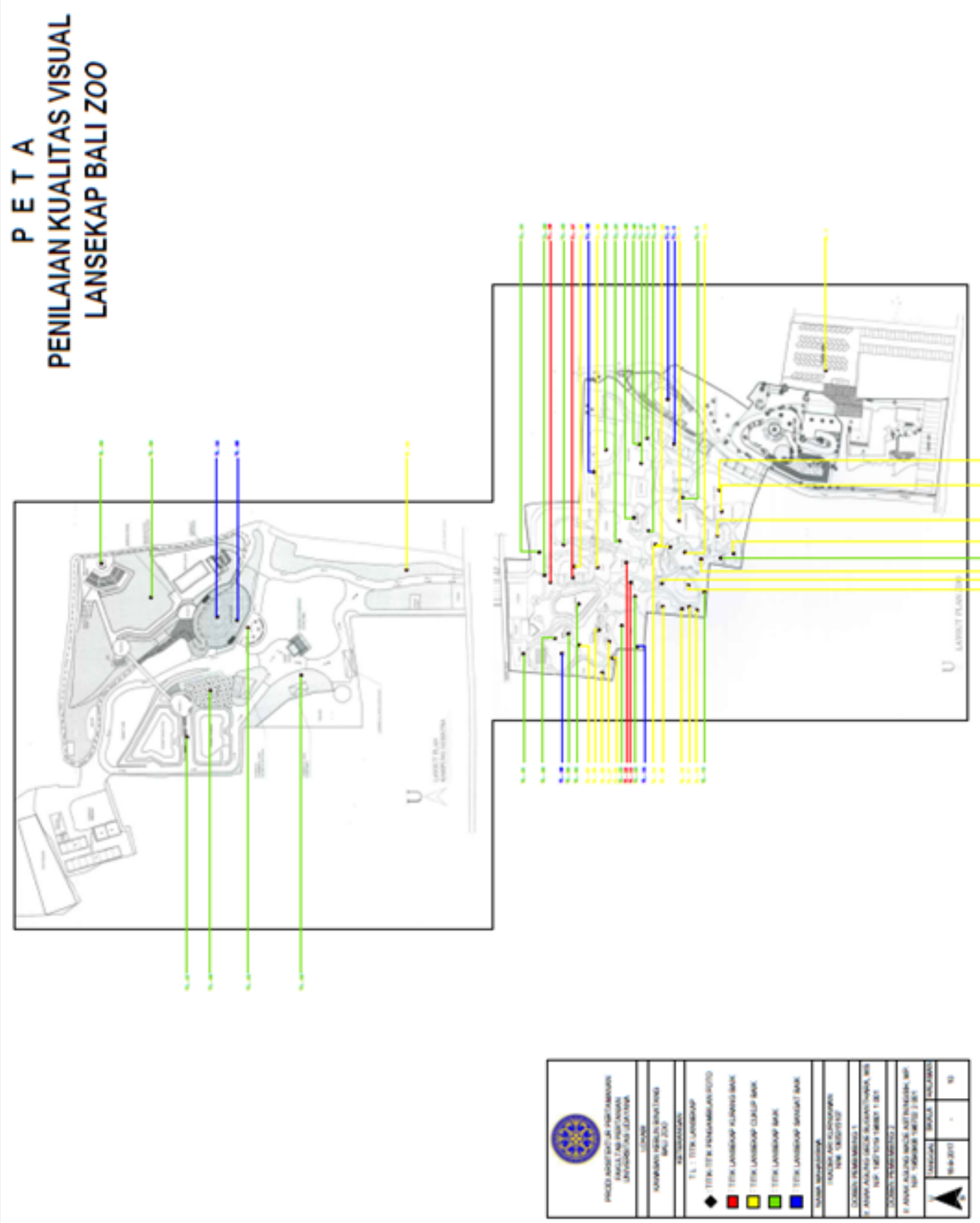

Gambar 4. Peta Penilaian Kualitas Visual Lansekap Bali Zoo 


\subsection{Penilaian Aspek Sapta Pesona Objek Wisata Bali Zoo}

Sapta pesona adalah tujuh unsur daya tarik wisata yang harus diwujudkan dalam rangka menarik minat wisatawan untuk berkunjung ke tempat wisata. Aspek sapta pesona yang sudah terwujud di objek wisata Bali Zoo terdiri dari unsur keamanan, ketertiban, kebersihan, kesejukan, keindahan, keramahan dan kenangan. Penilaian terhadap aspek sapta pesona dinilai oleh 30 responden yang merupakan pengunjung Bali Zoo.

\subsubsection{Penilaian Unsur Keamanan Bali Zoo}

Hasil penilaian responden terhadap aspek sapta pesona unsur keamanan Bali Zoo sebagian besar berada pada kategori cukup aman dan aman. Berdasarkan hasil survei, bentuk aksi unsur keamanan di Bali Zoo antara lain terdapat papan peringatan keamanan berfungsi melarang pengunjung melakukan aktivitas yang dilarang dalam rangka menjaga keselamatan pengunjung; aktivitas memberi makan dan foto bersama satwa didampingi petugas; terdapat aliran listrik mengelilingi kandang harimau yang berfungsi menjaga jarak satwa dengan pengunjung; serta terpasang kamera cctv pada lokasi tertentu.

Berdasarkan hasil survei, juga ditemukan masalah keamanan di Bali Zoo seperti tidak tersedia tempat penitipan barang pengunjung; tembok pembatas pada kandang kasuari cukup rendah, berbahaya bagi pengunjung; orangutan yang kurang bersahabat dengan pengunjung, biasanya orang utan ini suka melempari pengunjung dengan buah sisa makannannya. Hasil wawancara dengan Sudiarsa (2017) juga diketahui bahwa, satwa yang keluar atau kabur dari kandang masih sering terjadi, biasanya satwa yang pernah ke luar dari kandang yaitu satwa jenis rusa, burung, gibbon, orangutan dan harimau. Usaha yang dapat dilakukan untuk mengurangi masalah keamanan adalah pengadaan tempat penitipan barang, yang akan memudahkan pengunjung untuk menyimpan barang tertentu selama kunjungan. Kandang kasuari perlu ditambah pembatas yang lebih tinggi dengan penambahan pembatas besi maupun kaca untuk mencegah pengunjung melakukan kontak dengan satwa. Penambahan papan peringatan sebelum memasuki area kandang orangutan, mengingat orang utan tersebut gemar melempari pengunjung dengan sesuatu yang berada di dekatnya. Menurut Indonesian Society for Animal Welfare disingkat ISAW (2017), kandang satwa sebaiknya dilengkapi dengan sistem pintu masuk ganda yang memungkinkan staff untuk mengunci dua pintu. Sistem pintu ganda ini dapat mencegah terjadinya tindakan yang kurang hati-hati dan menyebabkan satwa melarikan diri.

\subsubsection{Penilaian Unsur Ketertiban Bali Zoo}

Hasil penilaian responden terhadap aspek sapta pesona unsur ketertiban di Bali Zoo menyatakan, sebagian besar berada pada kategori baik dan cukup baik. Berdasarkan hasil observasi, bentuk aksi aspek sapta pesona unsur ketertiban di Bali Zoo antara lain pengunjung mendapatkan brosur dengan informasi yang cukup jelas; pada masing-masing kandang satwa tersedia papan informasi dengan informasi spesifikasi dan deskripsi singkat satwa; tersedia papan petunjuk jalur untuk memudahkan sirkulasi; papan peraturan yang mengingatan pengunjung untuk berhati-hati selama berada di area kebun binatang. Berdasarkan observasi, juga ditemukan masalah ketertiban di Bali Zoo seperti kekurangan area parkir, khususnya saat musim liburan yang menyebabkan arus lalu lintas sekitar Bali Zoo menjadi macet; papan informasi yang hanya menggunakan bahasa asing tanpa didampingi bahasa Indonesia, hal ini cukup menyulitkan pengunjung dalam mendapatkan informasi khususnya bagi pengunjung lokal yang kurang mengerti bahasa asing.

Papan informasi dan peraturan dengan dua bahasa pokok yakni bahasa Indonesia dan bahasa Inggris akan memudahkan wisatawan dalam memperoleh informasi dan mengarahkan pengunjung untuk mentaati peraturan. Penambahan bahasa Indonesia pada papan informasi dan peraturan akan lebih memudahkan wisatawan, khususnya bagi wisatawan lokal. Usaha mencegah kemacetan dapat dilakukan dengan memperluas area parkir atau mencari lahan alternatif yang dapat dimanfaatkan sebagai area parkir sementara. Wiwik (2009) menyatakan, bahwa wisatawan akan merasa senang apabila tempat yang didatanginya berada dalam kondisi yang tenang dan teratur.

\subsubsection{Penilaian Unsur Kebersihan Bali Zoo}

Hasil penilaian responden terhadap aspek sapta pesona unsur kebersihan Bali Zoo sebagian besar berada pada kategori cukup bersih dan bersih. Berdasarkan survei, bentuk aksi unsur kebersihan di Bali Zoo antara lain tersedia tikar desinfektan untuk alasan kebersihan pengunjung; kebersihan kandang satwa dan lingkungan cukup bersih; tiga restoran bersih dan rapi; tersedia tempat sampah dan tempat cuci tangan; dan penampilan staff cukup bersih dan rapi. Berdasarkan survei, juga ditemukan masalah kebersihan di Bali Zoo antara lain kandang satwa tertentu yang kurang bersih, sehingga menimbulkan bau tidak sedap seperti pada kandang kasuari, rusa, binturong, dan area aviari; area kolam dan parit pembatas kandang satwa cukup kotor dengan dedaunan kering dan sampah sisa makanan pengunjung. 
Penambahan tanaman yang memiliki kelebihan pada aroma perlu dilakukan untuk meminimalkan aroma tidak sedap yang tercium di beberapa kandang satwa. Tanaman tersebut seperti tanaman kaca piring (Gardenia jasminoides), melati (Jasminum), sedap malam (Polianthes tuberosa), kenanga (Cananga odorata), dan kamboja (Plumeria). Peningkatan kebersihan pada area yang terdapat air juga perlu ditingkatkan guna mencegah timbulnya sumber penyakit bagi satwa maupun pengunjung. Penambahan tanaman seperti serai wangi (Cymbopogon nardus), daun selasih (Ocimum basillicum), geranium (Palrgonium graveolens), dan legundi (Vitex trifolia) dapat membantu mengatasi masalah nyamuk dan serangga lain karena aroma yang dihasilkan tidak disukai oleh nyamuk. Penambahan tempat sampah pada lokasi peristirahatan pengunjung juga perlu diadakan, lokasi ini merupakan salah satu lokasi berpotensi menciptakan sampah oleh pengunjung. Usaha mengedukasi pengunjung dengan papan peringatan untuk tidak membuang sampah sembarangan dan menjaga kebersihan lingkungan juga sebaiknya diadakan pada tempat istirahat ini guna mengajak wisatawan untuk menjaga kebersihan.

\subsubsection{Penilaian Unsur Kesejukan Bali Zoo}

Area zoo Bali Zoo dengan konsep hutan tropis didominasi oleh tanaman pohon dengan tajuk lebar, sehingga menyebabkan suasana area zoo menjadi lebih sejuk; tersedia beberapa kolam dengan suara gemericik air mancur buatan pada area tertentu menambah suasana sejuk. Berdasarkan wawancara dengan arsitek Bali Zoo, Gede 2017 menyatakan bahwa konsep lansekap yang dipilih untuk area Zoo merupakan konsep jungle atau hutan untuk dapat menciptakan suasana habitat asli dari masing-masing satwa, sedangkan konsep area Kampung Sumatera sudah lebih modern dengan perencanaan yang lebih baik. Berdasarkan hasil survei, juga ditemukan masalah kesejukan di Bali Zoo yaitu area Kampung Sumatera dan area parkir mobil dibagian atas cukup panas karena pohon yang ditanam masih dalam proses pertumbuhan.

Bali Zoo merupakan objek wisata lansekap buatan dengan berbagai jenis tanaman terutama jenis pohon dengan tajuk yang lebar dan tinggi sehingga memberikan kesejukan. Area Zoo sudah cukup sejuk, didominasi oleh tanaman pohon, sedangkan area Kampung Sumatera dan area parkir bagian atas masih kurang sejuk akibat tanaman pohon masih dalam proses pertumbuhan sehingga membutuhkan waktu untuk meningkatkan kesejukan. Kondisi tersebut cukup mempengaruhi penilaian responden terhadap unsur kesejukan Bali Zoo yang menyatakan, bahwa suasana lingkungan, sebagain besar berada pada kategori cukup sejuk dan sejuk. Usaha yang dapat dilakukan untuk mempertahankan bahkan meningkatkan unsur kesejukan Bali Zoo yaitu dengan memelihara penghijauan di lingkungan objek wisata Bali Zoo. Bali Zoo dapat menciptakan program penanaman pohon bagi wisatwan yang nantinya pohon tersebut diberi identitas wisatawan yang menanam. Wisatawan dapat mengadopsi satu tanaman di Bali Zoo dengan harapan wisatawan akan melakukan kunjungan ulang untuk melihat pohon yang mereka tanam.

\subsubsection{Penilaian Unsur Keindahan Bali Zoo}

Hasil penilaian responden terhadap aspek sapta pesona unsur keindahan Bali Zoo sebagian besar berada pada kategori cukup baik dan baik. Berdasarkan hasil survei, bentuk aksi dalam sapta pesona unsur keindahan di Bali Zoo antara lain keindahan lingkungan di dalam kandang satwa cukup indah; keindahan lingkungan di luar kandang juga cukup indah, adanya taman-taman dengan penataan yang cukup baik menambah keindahan lingkungan di luar kandang sehingga menimbulkan pemandangan yang baik. Berdasarkan hasil survei, juga ditemukan masalah keindahan di Bali Zoo seperti kurangnya unsur elemen vegetasi yaitu tanaman hias berwarna dan berbunga pada area zoo menyebabkan tapak menjadi kurang menarik, penambahan tanaman hias akan meningkatkan estetika lansekap secara visual; kurangnya tindakan penyulaman (penanaman kembali) pada taman dengan tanaman yang sudah mati.

Berdasarkan pengamatan, elemen vegetasi pada area Zoo terkesan monoton dengan didominasi oleh tanaman berwarna hijau. Kombinasi tanaman yang memiliki kelebihan pada warna dapat meningkatkan nilai estetika. Tanaman rusak dan mati juga banyak terlihat pada tapak, sehingga perlu usaha untuk mengatasinya yaitu dengan penyulaman. Tindakan penyulaman merupakan usaha mengganti tanaman yang sudah rusak maupun mati dengan tanaman baru yang lebih baik. Pengunjung yang berada pada objek wisata dengan keindahan yang baik akan tidak merasa bosan dalam menikmati aktivitas wisatanya. Hasil penelitian didukung oleh pernyataan Wiwik (2009) yang menyatakan, bahwa indah tidak berarti harus mewah. Objek wisata yang sederhana, nyaman, rapi dan bersih dapat menciptakan keindahan tersendiri.

\subsubsection{Penilaian Unsur Keramahan Bali Zoo}

Berdasarkan hasil survei yang dilakukan, bentuk aksi dalam sapta pesona unsur keramah-tamahan di Bali Zoo antara lain staff/ pegawai bersikap baik dan ramah terhadap pengunjung; tindakan memberi informasi secara sopan; tindakan memberikan pertolongan jika dibutuhkan oleh pengunjung. Hasil penilaian responden terhadap aspek sapta pesona unsur keramahan Bali Zoo sebagian besar berada pada kategori baik dan sangat baik. 
Keramahan merupakan salah satu kunci sukses pariwisata, senyum ramah yang tulus saat menyambut wisatawan adalah salah satu hal yang membuat mereka betah di tempat wisata. Unsur keramahan dapat diciptakan melalui pelayanan yang baik. Pelayanan Bali Zoo kepada pengunjung sudah sangat baik, terlihat dari sikap staff/ petugas yang baik dan ramah, siap membantu pengunjung ketika membutuhkan bantuan, menghormati pengunjung dan berpenampilan baik. Keramahan yang telah tercipta dengan baik ini harus dipertahankan untuk menunjang peningkatan aspek sapta pesona Bali Zoo.

\subsubsection{Penilaian Unsur Kenangan Bali Zoo}

Berdasarkan hasil survei, bentuk aksi sapta pesona unsur kenangan di Bali Zoo antara lain pengunjung terlibat langsung dalam atraksi, seperti memberi makan satwa, naik gajah, naik kuda poni, dan atraksi burung terbang; pengunjung dapat melakukan aktivitas petualangan malam di kebun binatang sambil menyaksikan atraksi tari kontemporer dan tari api; pengunjung juga dapat melakukan foto bersama dengan satwa. Kegiatan tersebut akan memberikan pengalaman tersendiri sehingga menjadi kenangan tidak terlupakan bagi wisatawan Bali Zoo. Hasil penilaian responden terhadap unsur kenangan Bali Zoo sebagian besar berada pada kategori cukup baik hingga baik.

Berdasarkan hasil survei, ditemukan masalah kenangan di Bali Zoo antara lain koleksi satwa yang ditampilkan masih belum lengkap. Masih banyak satwa langka yang belum terlihat sebagai penghuni Bali Zoo seperti komodo (Veranus komodoensis), tapir (Tapirus indicus), jerapah (Giraffa camelopardalis), unta (Camelus dromedaries) dan satwa langka lainnya. Kehadiran satwa langka yang lebih banyak dan beranekaragam diharapkan dapat memperlengkap koleksi satwa dan meningkatkan kualitas aspek sapta pesona objek wisata Bali Zoo khususnya untuk unsur kenangan.

\section{Simpulan dan Saran \\ 4.1 Simpulan}

Kualitas visual lansekap Bali Zoo terdiri dari kategori kurang baik, cukup baik, baik dan sangat baik.

2. Aspek sapta pesona yang terwujud di objek wisata Bali Zoo sebagian besar berada pada kategori cukup baik dan baik, ketujuh unsur tersebut terdiri dari keamanan, ketertiban, kebersihan, kesejukan, keindahan, keramahan, dan kenangan.

\subsection{Saran}

Saran Saran yang dapat diberikan dari penelitian ini bagi pengelola adalah mempertimbangkan hasil dari penelitian untuk pengembangan Bali Zoo sebagai objek wisata, bagi pengunjung adalah peningkatan partisipasi dalam menjaga kelestarian Bali Zoo, dan bagi mahasiswa yang hendak melakukan penelitian di Bali Zoo sebaiknya mempertimbangkan perluasan batasan analisis.

\section{Daftar Pustaka}

Bali Zoo. 2017. Situs Resmi Kebun Binatang Bali (Bali Zoo). Dapat diakses online pada http://www.balizoo.com/ (diakses pada tanggal 25 Juni 2016).

Indonesian Society for Animal Welfare (ISAW). 2016. Pengertian Kebun Binatang menurut Perhimpunan Kebun Binatang se-Indonesia (PKBSI). Dapat diakses online pada http://www.isaw.or.id/ (diakses pada tanggal 25 Juni 2016).

Laila, R. A. N. 2003. Evaluasi Estetik Lansekap Jalan Utama Kota Serang Menggunakan Simulasi Komputer. Skripsi. Institut Pertanian Bogor.

Meliawati. 2003. Kajian Karakteristik dan Elemen-Elemen Pembentuk Kualitas Estetika Lansekap Kota Bogor. Skripsi. Institut Pertanian Bogor.

Putri, D,A. 2014. Kebun Binatang Surabaya (Perancangan Ulang dengan Pengoptimalan Ruang Terbuka Hijau). Vol.3. No.1. Hal.2. Jurnal. Universitas Brawijaya.

Ruswan, M. 2006. Analisis Pengaruh Elemen Lansekap Terhadap Kualitas Estetika Lansekap Kota Depok. Skripsi. Institut Pertanian Bogor.

Sinaga, S. 2010. Potensi dan Pengembangan Objek Wisata di Kabupaten Tapanuli Tengah. Tugas Akhir. Universitas Sumatera Utara.

Wiwik, M. 2009. Panduan Dasar Pelaksanaan Ekowisata. Dapat diakses online pada http://unesdoc.unesco.org/ (diakses pada tanggal 21 Januari 2016). 